\title{
Literatura e audiovisual em José Mauro de Vasconcelos
}

\author{
Andrea Borges Leão* \\ https://orcid.org/0000-0001-8404-6767 \\ Edson Farias** \\ https://orcid.org/0000-0002-9406-3269
}

Nas margens da circulação simbólica

Quando José Mauro de Vasconcelos morreu, em 1984, Herberto Sales, então diretor do Instituto Nacional do Livro, foi convidado pelo Conselho Federal de Cultura para proferir uma homenagem ao escritor, um dos brasileiros mais traduzidos no mundo. A lista completa das edições estrangeiras dos livros de José Mauro precisaria ser organizada, e Sales não hesitou em procurar o amigo Walter Matos, que trabalhava na Editora Melhoramentos, à qual o escritor estava ligado por contrato, e poderia fornecer a informação solicitada.

Não foi difícil reproduzir os títulos do acervo das traduções de José Mauro guardados na empresa após a sua morte, salvo um em coreano do romance $O$ meu pé de laranja lima, até aquele momento desconhecido pela editora. De sua parte e em vida, José Mauro de Vasconcelos não tinha o menor controle sobre a circulação transnacional da sua obra. Foi em uma Bienal do Livro de São Paulo que Herberto Sales the deu a notícia da versão coreana do best-seller. O escritor a recebeu com surpresa e emoção. O que se devia obviamente ao fato de a Coreia do Sul não ser país signatário da Convenção de Berna, justifica Sales (1988, p. 432), complementando que precisou erguer uma "ponte postal de mar e nuvens" com cartas, notas e correções

\footnotetext{
' Universidade Federal do Ceará, Ceará, Brasil.

** Universidade de Brasília, Brasília, Brasil.
} 
de trabalho entre ele, no Brasil, e Dong Won Park, tradutora de seu romance Cascalho no país oriental. Retrospectivamente, percebe-se nessa confissão a importância estratégica da integração pessoal dos escritores brasileiros em redes de sociabilidades intelectuais ampliadas quando se trata de transpor fronteiras. Só assim, as trocas poderiam tomar corpo e solidez. Após o encontro entre os dois escritores na Bienal, Park, que também vertera $O$ meu pé de laranja lima, envia a Sales um volume desse romance em coreano, autografado e com dedicatória em português a José Mauro.

Se o repertório documental das fontes sobre a circulação do romance nacional, ou, generalizando um pouco, sobre o alcance da internacionalização do mercado cultural no Brasil, escapa ao controle das empresas editoriais, o que esperar dos criadores das próprias obras? A ponte postal de mar e nuvens construída entre Herberto Sales, Dong Park e José Mauro de Vasconcelos introduz a ideia central posta em discussão neste artigo: as condições de circulação e recepção internacional das obras constituem um fator de diferenciação nas carreiras literarias nacionais e, em decorrênca, favorecem capitais de reconhecimento e consagração só possíveis na confluência entre cânones nacionais.

O percurso do escritor José Mauro de Vasconcelos, cuja obra descreve movimentos entre a literatura e o audiovisual a partir de 1950, estabelece relações explicativas de alto rendimento analítico com a problemática da recepção transnacional da produção brasileira. E traz como problema suplementar a circulação no interior do espaço nacional. Da escrita às telas do cinema e da televisão, destas ao espetáculo de teatro e do carnaval, a literatura popular sentimental do escritor resiste para além dela mesma ao ser recriada e ampliada em suportes da cultura massiva. As adaptaçôes do livro para os meios de comunicação são simultâneas à transposição de fronteiras linguísticas nacionais, de acordo com os imperativos do entretenimento de cada época e do gosto de cada público. A sincronia entre literatura e carnaval esteve, portanto, obediente à codificação pela qual o audiovisual se estendia para além das mídias (cinema e televisão), por constituir o desfile como linguagem artística e plataforma comunicacional capaz de fazer convergirem diferentes suportes e de promover diversas intertextualidades. Procuramos, em especial, mostrar como literatura e carnaval compartilham a propriedade de verter elementos do real histórico em ficção, em uma cumplicidade criativa capaz de promover a evasão pelo entretenimento.

O meu pé de laranja lima, publicado em 1968, indicado ao prêmio Jabuti de 2019 e finalista na categoria "Livro brasileiro publicado no exterior", não é um sucesso do passado. Tampouco seria descartável como vaticinara a crítica à época da sua publicação. Há mais de cinquenta anos permanece no patrimônio da cultura universal em traduções por 23 países e quinze idiomas (Aguiar, 2018, p. 217), comprovando eficácia na formação de novos públicos e na longevidade do prestígio de seu criador. 
Nossa hipótese é a de que a condenação moral da crítica especializada aos romances sentimentais de José Mauro de Vasconcelos aliada ao triunfo simultâneo da recepção nacional e transnacional, textual e visual, se o empurraram para as margens da circulação simbólica, igualmente criaram condições favoráveis para a autonomia relativa da literatura brasileira. Procuramos mostrar que a obra do autor, em um momento específico de consolidação da indústria cultural, se internacionaliza sem desnacionalizar-se. Ou, como observa Pierre Bourdieu (2001), comprova que os graus de internacionalização, medidos pelos números de edições e vendas, pelos idiomas das traduções, locais de publicação, trajetórias e práticas, espaços de sociabilidades comuns aos agentes etc., são indicadores do grau de autonomia da produção nacional. Assim, o estudo da circulação da obra de José Mauro de Vasconcelos torna-se ponto de referência do que Pascale Casanova (2007) entende como possibilidade de recurso ou saída face às estratégias de marginalização e censura que marcam a recepção crítica de um autor em um campo nacional específico. Esse recurso, quando utilizado sob a confluência de cânones nacionais, modifica e cria novas posições e lógicas de consagração, redefine atividades de circulação e critérios objetivos de classificação dos pares autonomia/ heteronomia, centro/periferia. No caso de José Mauro de Vasconcelos, indica um modo de participação no que se estrutura como cultura popular de massa no Brasil e torna-se patrimônio literário universal, invertendo o sentido da circulação das obras, no exterior.

\section{Literatura brasileira de exportação: popular e curricular}

José Mauro de Vasconcelos nasceu no dia 26 de fevereiro de 1920, em Bangu, bairro da zona oeste do Rio de Janeiro, no seio de uma família modesta ${ }^{1}$. Sua figura de mestiço, com pai português e mãe indígena, evoca um lugar de origem propício ao encontro entre culturas. Com a morte precoce dos pais, foi adotado pelo padrinho, que vivia em Natal, Rio Grande do Norte, cenário do seu romance Barro Blanco. A nova família o acolhe como menino "dado", o que significa alguém reconhecido como de fora do núcleo parental. Somada à experiência precoce da exclusão familiar, teve educação escolar "um tanto indisciplinada" assistemática, aliada ao incentivo aos treinos de natação no rio Potengi e no mar. José Mauro foi medalhista em várias provas de grande distância.

1. Os dados biográficos do escritor foram extraídos do ensaio crítico de Luiz Antônio Aguiar na edição comemorativa de O meu pé de laranja lima (Aguiar, 2018) e do livro José Mauro de Vasconcelos: o homem e a obra (Vasconcelos, 1969). 
No primeiro ano do curso ginasial, aos dez anos, leu os romances de Graciliano Ramos, Paulo Setúbal e José Lins do Rego. O gosto espontâneo pela leitura será usado como trunfo do autodidatismo reivindicado pela memória do adulto. Após o secundário, inicia graduações sequenciadas nas faculdades de Medicina, Direito, Desenho e Filosofia, sem, contudo, concluir nenhuma. Em 1952, parte para a Espanha com o auxílio de uma bolsa de estudos em Salamanca. Fica apenas três dias na nova universidade, partindo para Madri, Itália e França por conta própria. De volta ao Brasil, deixa Natal a bordo de um navio cargueiro e se estabelece no Rio de Janeiro, onde trabalha como lutador de boxe, depois parte para o trabalho de carregador de bananas em uma fazenda em Mazomba, no interior fluminense. A próxima experiência é como pescador no litoral do mesmo estado do Rio, antes de se mudar para o Recife, onde leciona no ensino primário, também para pescadores. Anos depois, segue em direção ao Centro-Oeste na companhia dos irmãos Villas-Bôas, Orlando, Cláudio e Leonardo, conhecendo os índios do Xingu e os Carajás. Foi ainda modelo da Escola Nacional de Belas Artes (o Monumento à Juventude, de Bruno Giorgi, é inspirado nele), pintor, desenhista e escultor, bailarino e ator de cinema, teatro e televisão.

O escritor Lêdo Ivo² referia-se, queixoso, ao modo descontínuo com que José Mauro exercia a atividade literária e participava de universos culturais diferentes como uma "mania ambulatória". O que diz muito sobre o debate moral e a controvérsia da crítica nacional em torna de sua obra. A representação da infância marginalizada nas relações de interdependência com os adultos, sem dúvida, preparou a recepção de seu personagem-farol, Zezé, graças ao qual conseguiu estabilidade no êxito das vendas, algumas adaptações além do suporte livro e um fluxo de traduções que colocaram $O$ meu pé de laranja lima, seu primeiro best-seller, em circulação mundial. Só assim, a queixa de Ivo - errância, inquietação, nomadismo - pode ser deslocada para o que Bernard Lahire (2006) entende como ambiguidade estrutural na vida do escritor que pratica a literatura, mas exerce outras atividades remuneradas como segundo métier. Ou melhor, as propriedades atribuídas a José Mauro por Ivo revelam a lógica heterônoma na carreira de um escritor que está em vários lugares ao mesmo tempo sem pertencer a nenhum, em decorrência da instabilidade nos níveis de reconhecimento ${ }^{3}$.

2. Referência ao escritor Lêdo Ivo no texto de apresentação do autor publicado no livro José Mauro de Vasconcelos: o homem e a obra (Vasconcelos, 1969).

3. A propósito das diferenças de estratégias e percursos da profissionalização literária no século xx, Bernard Lahire (2006) atenta para o risco redutor do enquadramento do indivíduo em um exclusivo universo como base de diferenciação de sua atividade. Para o sociólogo, torna-se urgente a especificação da teoria dos campos, de Pierre Bourdieu, em cada modelo morfológico e experiência histórica, considerando as propriedades e a relativa autonomia com relação às instâncias de regulação, como Estado e mercado. 
Importa compreender, pois, quais posições um escritor como José Mauro ocupa no vaivém do jogo literário, as estratégias e resultados de suas práticas, as correlatas e múltiplas formas de illusio, crenças, disposições incorporadas e reconhecimento de público e crítica alcançados.

Assim, José Mauro de Vasconcelos, uma figura individual e coletiva de jogador, começa a escrever em 1940. Sua estreia no jogo literário se deu com a de Guimarães Rosa. Banana Brava e Sagarana, do mineiro, chegaram juntos às livrarias, em 1942. Houve até quem os comparasse em envergadura e originalidade. Alcântara Silveira, por exemplo, julgou, nas palavras do escritor, “o estilo de Guimarães Rosa formidável, mas como ficcionalista eu era melhor”, lembra em entrevista concedida a Audálio Dantas, publicada na revista Realidade ${ }^{4}$. Em 1943, na Editora Agir, José Mauro conheceu a novata Clarice Lispector, que acabara de publicar Perto do coração selvagem.

No início da carreira, foi aclamado como escritor de literatura regional. Os romances de estreia Banana Brava e Barro Blanco são bem recebidos pela crítica especializada. Luís da Câmara Cascudo escreve uma apresentação elogiosa ao Banana Brava, publicado em 1944 pela Agir. Cascudo traça o retrato do escritor bandeirante que marcha para o Oeste em trens de ferro e caminhões, em longas caminhadas para subir as águas escuras do Araguaia, "caminho do ouro e do diamante, no reino bruto dos-que-se-atiram-primeiro" (Cascudo, 1944, p. 2). Compara-o ao norte-americano Jack London: "Vasconcelos dirá: eu sou a grande aventura”. O personagem Zé, do romance Doidão, lançado em 1963, é um dos que melhor objetivam, no elenco do autor, a educação sentimental pela aventura. Como todo bom aventureiro, aos dezenove anos Zé traz os mapas da geografia abertos na memória. "Mato Grosso. Selva, Goiás. Selva. Índios. Selva. Ilha do Bananal. Maior ilha fluvial do mundo. Selva. Meu Deus!" (Vasconcelos, [1963] 1972, p. 26) - são os pontos cardeais que alimentam o seu desejo da partida como disposição para uma "vagabundagem", reconstruída pelo escritor como atributo originário do "sangue indígena”. Mas seu desejo dos confins, para ficar com uma expressão de Sylvain Venayre (2002, p. 19), nutria-se também de outra fonte: o amor pelas figuras do cinema norte-americano e por Carmem Miranda, grande aventureira da moderna indústria da cultura. Assim, o lugar da aventura em José Mauro de Vasconcelos, o viajante, vai sendo construído na assimilação do exotismo tropical pelos gêneros do entretenimento - literatura seriada, novela de televisão, desfile de carnaval - como informação, pedagogia sentimental ou simplesmente transmissão de experiência de vida.

4. Matéria assinada por Audálio Dantas e intitulada “José Mauro: 18 livros e muitos amores”. Publicada na revista Realidade, da editora Abril, de outubro de 1979 (Dantas, 1979). 
O segundo romance, Barro Blanco, ambientado nas salinas do Rio Grande do Norte, é publicado pelo Instituto Progresso Editorial de São Paulo em 1948. O suplemento "No Mundo dos Livros" da revista O Cruzeiro, de 30 de outubro do mesmo ano, também o compara a Jack London, "pelo espírito de aventura e compaixão humana de suas histórias", e conclui: Barro Blanco é um livro brasileiro5. Anos depois, o adjetivo "bandeirante literário" passa a funcionar como capital de experiência delimitador da lógica de circulação internacional de seus livros, objetos também viajantes.

José Mauro conta que de sua primeira viagem à selva, abrindo mato a peito, morando com índios e se aventurando no garimpo, nasceu Barro Blanco, livro-experiência que lhe "custou a perna direita quebrada em três lugares”. Na volta da aventura, subindo o rio Tocantins, trazia o texto pronto na cabeça, escreveu-o em 27 dias. Chegando a São Paulo, onde residia na casa de uma tia, resolveu cuidar da perna paralisada. Viajou ao Rio de Janeiro a fim de se tratar em um hospital de indigentes, lá conheceu um frade dominicano que leu os originais do livro e os levou para a Editora Agir. Vale notar que o destino de Barro Blanco, como na história sobre o garimpo de Banana Brava, foi decisivo na autenticação imaginária da figura do bandeirante moderno. O novo livro denunciava a exploração dos trabalhadores nas salinas do Rio Grande do Norte por grandes empresas instaladas na região, como a Matarazzo. De São Paulo, exatamente Ciccillo Matarazzo sentiu-se especialmente tocado pela leitura e procurou conhecer o jovem autor José Mauro de Vasconcelos. Firmaram uma longa amizade. O criador da Bienal Internacional do Livro e do Museu de Arte Moderna de São Paulo e fundador da Companhia Cinematográfica Vera Cruz, entre outros empreendimentos, pagou quase todas as cirurgias da perna de José Mauro, além de presenteá-lo com máquinas de escrever: "Ganhei catorze máquinas de escrever dele. Quando eu acabava de escrever um livro e não tinha dinheiro para comer, vendia a máquina, e o Ciccillo me dava outra” (Dantas, 1979). Anos após, o amigo mecenas o provocaria: “- Deixa de ser besta. Você é mais rico do que eu”.

O meupéde laranja lima, publicado pela editora Melhoramentos em 1968, conta a história sentimental de um garoto pobre da periferia do Rio de Janeiro. Esse romance autobiográfico sucede o Doidão, que já apresentara ao público o protagonista Zezé adolescente, compondo a trilogia do autor junto a Vamos aquecer o sol. Hoje, O meu pé de laranja lima forma a coleção denominada "Série José Mauro de Vasconcelos" da editora, indicando uma orientação de leitura sequenciada.

5. Exemplar de O Cruzeiro, do dia 26 de março de 1949. Disponível em http://memoria.bn.br/DocReader/DocReader.aspx ?bib=003581\&PagFis=63603\&Pesq=Jos\%C3\%A9\%20Mauro\%20de\%20Vasconcelos, consultado em 4/1/2020. 
Em O meu péde laranja lima, as aventuras de Zezé no mundo adulto - nas ruas, na casa e na escola -, as confidências trocadas com uma árvore, a experiência do sofrimento e da dor com parentes e amigos também são ambientadas no bairro onde nasceu o escritor. Não foi sua intenção primeira destiná-lo às crianças. Mas, como as publicações não são arbitrárias, os editores cuidaram logo de organizar e classificar O meu pé de laranja lima como literatura juvenil, a fim de orientar a recepção para essa faixa etária consumidora em expansão no mercado editorial brasileiro dos anos 1970. E, apesar de ter recebido, no ano da sua publicação, o troféu Roquette Pinto, premiação da televisão brasileira pela primeira vez concedida à literatura, e de encher a gaveta do escritor com cartas de leitores de variadas línguas, esse livro dá início ao lado negativo da fortuna crítica de José Mauro de Vasconcelos. É o ponto de inflexão entre o bandeirante moderno e o coletor de laranjas-limas.

No espaço de produção brasileiro, a questão maior do best-seller não se deve apenas ao êxito de vendas, mas ao problema de rebaixamento do prestígio de que se revestem, por exemplo, obras como a de José Mauro, na medida em que se amplia o circuito da sua recepção, colocando também o escritor na incômoda posição de best-seller. Esse termo, observa Fernando Pinheiro (2014, p. 245), opera deslizamento semântico propício a um sistema de classificação literário que passa a avaliar a obra pelos critérios do mercado, e não mais pelos critérios estéticos. Ou melhor, abrindo caminhos para o escritor Paulo Coelho, estudado por Pinheiro, esse julgamento, que também se aplicava nos anos de 1970, nos oferece a chave de recepção da obra de José Mauro de Vasconcelos: "desqualificação classificatória que recusa a seus livros o estatuto de literatura" (Pinheiro, 2014, p. 246).

Em 1979, O meu péde laranja lima acumulara uma tiragem de mais de 2,5 milhões de exemplares, só no Brasil, após o sucesso da sua reprodução audiovisual. Pode-se, no entanto, formular o problema best-seller de outro modo, perguntando como um livro constrói categorias e comunidades de leitores pelo mundo afora, sincrônica e diacronicamente. À maneira dos heróis dos folhetins do século xIx e do paradigmático pai Tomás, de A cabana do pai Tomás, romance da escritora norte-americana Harriet Beecher Stowe, publicado em 1851, evocados por Jean-Yves Mollier (2019) como ilustrativos da profunda penetração da forma narrativa do melodrama no espaço social, o que circulava no romance de José Mauro e, por conseguinte, inscrevia o Brasil na literatura mundial de exportação eram os tipos sociais construídos nas narrativas. Destacam-se, nessas construções, o índio sul-americano, as crianças mestiças e demais figuras do jogo colonial, como o português. Vale lembrar que as configurações narrativas em torno de personagens recorrentes - Zezé atravessa a trilogia autobiográfica composta, como já assinalamos, por Doidão (1963), O Meupé de laranja lima (1968) e Vamos aquecer o sol (1974) -, se provocam vales de lágrimas, 
são também capazes de divertir e informar. Na lógica do entretenimento da cultura nos anos de 1970, o apelo sentimental, aliado à construção lúdica da criança indígena, reposicionava a literatura brasileira no circuito mundial. Essa pode ser uma chave do sucesso de José Mauro de Vasconcelos ao aproximar leitores de várias línguas.

A mesma comparação entre sua obra e a de Harriet Stowe estabeleceu o sociólogo Gilberto Freyre (2010, p. 102) em entrevista ao cronista pernambucano Renato Carneiro Campos, publicada no Diário da Noite, de 1970. Campos perguntou a Freyre se considerava maliciosa uma aproximação entre José Mauro e o popularíssimo Jorge Amado. E a seu ver, responde o sociólogo, haveria ao menos dois ou três Jorges Amados, em se tratando de literatura. Um deles guardava afinidades com escritores “marginalmente literários, mas não sociologicamente desprezíveis, como José Mauro de Vasconcelos, cujo vendidíssimo livro reproduziu, entre nós - é claro que em menor escala -, o caso do sucesso, no século passado, nos Estados Unidos de A cabana do pai Tomás", conclui. Tudo leva a crer que o paralelo entre obras de tradições literárias desiguais, do ponto de vista do acúmulo de capital de reconhecimento e da língua original de publicação, situa o escritor brasileiro em um patamar de consagração no plano internacional.

\section{A recepção na Argentina: um espaço de mediações}

As condições sociais dos processos de recepção, observa Joseph Jurt (2014), seja pela crítica especializada, seja pelos leitores comuns, tornam-se requisitos fundamentais para o conhecimento da gênese dos campos internacionais e apontam saídas para a elucidação da problemática das assimetrias na circulação dos modelos literários. Qual atração poderiam exercer os tipos sociais veiculados na literatura sentimental popular brasileira? Não se podem desconhecer a centralidade dos tradutores nem suas mediações na trajetória de José Mauro de Vasconcelos. São as inter-relações entre eles que propiciam deslocamentos de sensibilidade, formação de disposições e movimentos psicogenéticos de um leitorado comum circunscrito na mobilidade do livro. Assim como o da coreana Dong Won Park, o trabalho de tradução de Haydée Mercedes Jofre Barroso, no âmbito hispano-americano, tem muito a dizer sobre a inversão da circulação literária do Brasil - país historicamente importador e cuja língua ocupa posição periférica no mercado internacional das traduções - para a Argentina e a Espanha ${ }^{6}$. Seu projeto de tradução conferiu a Vasconcelos prestígio e reconhecimento. Quando estouraram as vendas de $O$ meu pé de laranja lima, José Mauro recebia em média cinquenta cartas por semana de leitores espalhados pelo mundo. Movia-se

\section{A Editora El Ateneo, com sede em Buenos Aires.}


entre a "ternura dos leitores e a impiedade dos críticos". Vejamos as valências abertas pela obra do escritor em direção ao continente americano, ao Atlântico e à Europa.

Na monografia que consagrou ao escritor, Vida y Saga de José Mauro de Vasconcelos (Barroso, 1978, p. 1, 2), publicada pela El Ateneo Editorial, de Buenos Aires, a casa do autor em língua espanhola, Haydée conta que, num belo dia de fins dos anos 1970, o editor Pedro García presenteou-a com um exemplar de $O$ meu pé de laranja lima e em seguida solicitou a sua opinião "sobre as possibilidades que o referido romance poderia ter no mercado de língua castelhana”. Já o tendo lido e apreciado em português e, sobretudo, já sabendo que a obra do autor era conhecida na Europa, a opinião de Barroso foi absolutamente entusiasmada. O passo seguinte foi a contratação dos direitos de tradução do texto com a Editora Melhoramentos. Nesse ínterim, Haydée inicia uma amizade epistolar com o autor. Prometeu se manter fiel à simplicidade coloquial de um estilo que a encantava, "e satisfazê-lo na mesma medida em que ele a havia satisfeito com sua belíssima história: pelo menos assim dizíamos mutuamente - havia outro idioma que mudava de nome mas não a essência de suas palavras" ". Assim, foi publicado Mi planta de naranja-lima, incluindo José Mauro na literatura argentina ${ }^{10}$.

Para Gustavo Sorá (2003, pp. 180-185), a figura de intermediária de Haydée Barroso representa um ponto de mutação entre a velha crítica erudita e um novo modelo praticado por carreiras intelectuais que se firmavam no jornalismo e na universidade. Neta de proprietários de terras no Brasil e tendo aprendido o português em família, contou com a ajuda da tia, Zelma Barroso de Oliveira, que havia sido cônsul do Brasil na Argentina, para estudar Letras e Jornalismo na Universidade do Rio de Janeiro, por cinco anos. No retorno a Buenos Aires, continua Sorá (2003, p. 181), em meados dos anos 1960, "trazia o reconhecimento do Prêmio Simón Bolívar, que outorgava o Comitê de Intercâmbio Cultural Panamericano, e os originais de um livro que no seu título manifestava o projeto autoral de Haydée Barroso: Esquema histórico da literatura brasileira" ${ }^{11}$. Trabalhando como funcionária do

7. Dantas (1979). Matéria assinada por Carmen Cagno e intitulada "Um novo round: Zé Mauro versus crítica" (Cagno, 1979).

8. No original: "sobre las posibilidades que la dicha novela podría tener en el mercado de habla castellana."

9. No original: "y haberle satisfecho en la misma medida en que él me satisfizo a mi com su bellísima historia: por lo menos así nos lo hemos dicho mutuamente - ya tenía otro idioma que cambiaba de nombre pero no de esencia a sus palabras."

10. Sobre o debate crítico aberto, nos anos de 1970, em torno da obra do autor no Brasil e na Argentina, consultar Leão (2018).

11. No original: "traía el reconocimiento del Premio Simón Bolívar, que otorgaba el Comité de Intercambio Cultural Panamericano, y los originales de um libro que en su título manifestaba el proyecto autoral de Haydée Barroso: Esquema histórico de la literatura brasileña”. 
Setor Cultural da Embaixada do Brasil em Buenos Aires, consolida seu percurso crítico-autoral vertendo para o espanhol Jorge Amado e publicando uma biografia de Monteiro Lobato, antes do ensaio que sairia, em 1978, sobre José Mauro de Vasconcelos. O posto na embaixada lhe possibilitou inúmeras viagens a Brasil, França, Portugal, Itália e Estados Unidos, nota Sorá (2003, p. 182), além da promoção de importantes coedições, como as que apareceram pela Sudamericana. Juntar o seu nome ao de Vasconcelos conferiu-lhe renome como tradutora, conclui, sobretudo pelo trabalho de apresentação dos livros do escritor nas escolas.

A partir de 1970, começa o sucesso escolar de José Mauro de Vasconcelos na Argentina. Essa foi mais uma via de transmissão aberta por Haydée Barroso. Como as edições do escritor se esgotavam rapidamente, criando verdadeira massa de leitores originários de um "de los fenómenos más curiosos que haya dado la literatura en el país" (Barroso, 1978, p. 159), a tradutora resolveu agrupá-los publicando as cartas que lhe enviavam sobre o que chamavam ternamente "Mauro de América". Eram jovens estudantes de colégios secundários, entre catorze e dezessete anos, e crianças de escolas primárias que liam o escritor por orientação curricular. Para essa comunidade de sentimentos e identificações mútuas, hispano-americana, adentrar o mundo do livro era o mesmo que adentrar a biografia do autor. Queriam saber se José Mauro era de fato o Zezé ou seu pai literário, se tinha mulher e filhos no Brasil, se era feliz ou solitário, se era amado pelos jovens de outros países, se voltaria a escrever mais histórias do Zezé, se os temas eram escolhidos pelos leitores etc. José Mauro, perguntavam, responderia cartas acaso as recebesse da Argentina? Entre os anos de 1975 e 1976, Haydée percorreu as escolas de seu país apresentando o autor e a sua obra. Ao todo, organizou encontros em 25 instituições estatais, religiosas e particulares da capital, da província de Buenos Aires e da Grande Buenos Aires. Segue uma pequena amostra das cartas recebidas pela tradutora:

Querida senhorita,

Me chamo Patrício. Tenho 11 anos e moro em Humberto I, N. [...] Lhe escrevo esta carta com o objetivo de saber sobre a vida de José Mauro de Vasconcelos. E eu quero dizer que o livro traduzido por você, de Zezé, é muito lindo e triste. Eu penso que Vasconcelos viveu esse livro e tudo o que relata é certo. Quero saber se você poderia recomendar algum outro livro de Vasconcelos que eu possa ler. Vou a escola n. 10 de Quilmes, estou no 6. Ano e minha professora é a senhorita [...]. Agora lhe quero fazer perguntas: Como é a vida de Vasconcelos? Se casou? Tem filhos? Vive atualmente? Por favor, peço que me responda, e muito obrigado (Barroso, 1978, p. 160) $)^{12}$.

12. No original: "Querida señorita, Me llamo Patricio. Tengo 11años y vivo en Humberto I, N. [...] Le 
Senhora

Sou aluno da escola do Padres Salesianos, me chamo Ricardo, e moro em [...]; estou lendo, junto com meus companheiros, o livro de Vasconcelos Mi planta de naranja-lima, e depois deveremos ler Rosinha, mi canoa. Estou gostando muito das coisas que ele conta, e creio que também gostarei do outro. Quero pedir que faça chegar essa carta a Vasconcelos, e que diga a ele que as crianças argentinas querem muito conhecê-lo, e que oxalá me responda, posso ler para todos os meus companheirinhos as coisas que ele me conte. Sobretudo queremos saber com quem e como mora, e que você diga a ele que oxalá venha a Buenos Aires para falarmos com ele, porque como disse minha mãe escutá-lo não é o mesmo que lê-lo. Mas que igualmnete nos responda. Muito obrigado por fazer o favor que lhe peço da minha terra patagônica. Ricardo. (Barroso, 1978, p. 160) ${ }^{13}$.

É certo que toda leitura de evasão provoca facilmente identificações. Nos encontros escolares, Haydée satisfazia as expectativas dos jovens contando fatos pitorescos e anedóticos da vida do escritor, detalhes de sua família e das atividades profissionais na literatura, no cinema etc. Não deixava, porém, de falar sobre o estilo, as características da prosa, o tratamento das paisagens, dos tipos e dos diálogos. José Mauro de Vasconcelos tornava-se uma celebridade que transborda a literatura. Haydée Barroso não apenas confirma o reconhecimento internacional do escritor pelo trabalho de mediação crítica, com sua entrada no cânone da literatura juvenil de língua espanhola, como também nos coloca o problema suplementar de um regime de autoria que busca distinção justo no sucesso comercial.

$\mathrm{Na}$ França, os educadores manifestavam preocupação com todo esse debate sobre o traçado sentimental que orientava a recepção transnacional da obra do escritor. No dia 31 de março de 1972, Béatrice Robillard, do Centre National du Livre Pour

escribo esta carta a causa de saber sobre la vida de José Mauro de Vasconcelos. Y le quiero decir que el libro que tradujo usted, de Zezé, es muy lindo y triste. Yo pienso que Vasconcelos vivió ese libro y todo lo que redacta es cierto. Quiero saber se usted me puede recomendar algún otro libro de Vasconcelos que yo pueda leer. Voy a la escuela N. 10 de Quilmes, estoy en 6. Grado y mi maestra es la señorita [...]. Ahora le quiero hacer preguntas: Qué es de la vida de Vasconcelos? Se caso? Tiene hijos? Vive actualmente? Por favor, le pido que me conteste, y muchas gracias. Patricio" (Barroso, 1978, p. 160).

13. No original: "Señora, Soy alumno de la escuela de los Padres Salesianos, me llamo Ricardo, y vivo en [...]; estoy leyendo, junto con mis compañeros, el libro de Vasconcelos Mi planta de naranja-lima, y despué deberemos leer Rosinha, mi canoa. Me están gustando mucho las cosas que él cuenta, y creo que el otro también me gustará. Quiero pedirle que le haga llegar esta carta a Vasconcelos, y que le diga que los niños argentinos lo queremos mucho conocerlo, y que ojalá me conteste, así le puedo leer a todos mis compañeritos las cosas que él me cuente. Sobre todo queremos saber con quién vive y cómo vive, y que le diga usted que ojalá que venga a Buenos Aires para hablar con él, porque como dice mi mamá no es lo mismo escucharlo que leerlo. Pero que igual nos conteste. Muchas gracias por hacer el favor que le pido desde mi tierra patagônica. Ricardo” (Barroso, 1978, p. 160). 
Enfants, órgão então ligado ao Ministério da Cultura e da Comunicação, encontra-se com duas bibliotecárias do Rio de Janeiro e inicia uma conversa sobre Mon bel oranger, título em francês de $O$ meu pé de laranja lima, traduzido por Alice Raillard para a editora Stock. Robillard declara no boletim de análise dos livros infantis que fora informada sobre a reação crítica adversa por parte de certos intelectuais que consideravam a obra de José Mauro excessivamente sentimentalista. Segundo a francesa, a educadora brasileira que encontrara trabalhava numa biblioteca de Bangu, bairro onde se ambientava o romance e, por isso, estando imersa na atmosfera do livro, falaria dele com propriedade. Aos críticos, Vasconcelos respondia: "Fiz um livro para as pessoas que vivem e não para os intelectuais: não é um livro de elite" ${ }^{14}$. Já no parecer de análise dos livros para crianças emitido por Jacqueline Michaud, da Biblioteca La Joie Par Les Livres, a capacidade de imaginação sem limites do personagem Zezé desafiava a dura realidade da vida da infância pobre brasileira. Nesse parecer, o herói é tomado na moderna variação do tipo exótico presente na literatura romântica: "um pequeno diabo que sabe ler sem jamais ter aprendido"; e noutra passagem, "através da linguagem e da consciência dessa criança aparece um mundo onde a miséria se aproxima do maravilhoso e a ternura da crueldade" (Idem). Mon bel oranger, para a crítica francesa, se tornava, ao mesmo tempo, melodrama maravilhoso e cruel, produzindo novos sentidos e modulando sensibilidades enquanto objeto de troca intercultural. Com isso, operando em diferentes escalas, o melodrama compõe um ingrediente fundamental de processos psicogenéticos pelos quais se delineiam padrões de subjetividades referidos à cultura popular de massa.

Na Feira do Livro de Buenos Aires de 1979, ano proclamado pelas Nações Unidas como Internacional da Criança, José Mauro dava banhos de popularidade nos outros escritores brasileiros ${ }^{15}$. Acompanhavam seus livros no estande do Brasil 4 mil títulos em diversos gêneros e coleções de autores como Jorge Amado, Vinicius de Moraes, Fernando Sabino, Carlos Drummond de Andrade, Lygia Fagundes Telles, Clarice Lispector, e os coeditados pela Embaixada do Brasil e pelas empresas locais. Nessa edição da feira, José Mauro teve dupla participação, no original português e em espanhol, este exposto no estande da livraria de Barcelona da El Ateneo, só ficando atrás de Jorge Amado, oferecido em português e espanhol, na Losada, mas também em árabe. Só restou a Mário Fittipaldi, então presidente da Câmara Brasileira do Livro, comemorar o êxito das vendas. Chamou-lhe a atenção, no final da feira, um

14. No original: “J'ai fait un livre pour les gens qui vivent et non pour les intellectuel; c'est ne pas un livre d'une elite." Documento intitulado Bulletin d'Analyses de Livres pour Enfants, 1971. Consultado na Bibliothèque National de France, 2019.

15. Matéria intitulada "Feira do Livro de Buenos Aires: 100 mil títulos para meio milhão de compradores", publicada no Jornal do Brasil, do Rio de Janeiro, a 17 de março de 1979 (Machado, 1979). 
casal com bebê de colo que lhe pediu para efetuar o pagamento em cheque das obras completas de José Mauro de Vasconcelos.

Esse episódio evoca uma passagem de Câmara Cascudo (1944, p. 4) na apresentação ao romance Banana Brava: enquanto outros meninos iam para a escola trazendo o lanche preparado pela mãe, Vasconcelos viera "fazer o Rio, com a naturalidade de um conquistador quinhentista”. Tudo leva a crer que o modo como organizou sua intervenção no espaço literário, até mesmo a orientação de um projeto criativo, tem a ver com as atividades aparentemente desconexas que exerceu às margens da circulação simbólica. Seguir a lógica da produção da cultura audiovisual era a sua forma de viver e reivindicar uma independência para a autoria literária, embora o requisito fundamental para o reconhecimento duradouro tenha sido o percurso transnacional de sua obra.

\section{Literatura e audiovisual: as releituras do carnaval}

Agora veremos de que modo a problemática de base posta neste ensaio encontra expressão nas releituras dos romances pelas novelas de televisão e pelo espetáculo do carnaval. Antes, José Mauro também participou do cinema nacional. Em 1956, o romance Arara vermelha é distribuído pela Columbia Pictures do Brasil, com Tom Payne na direção e elenco formado por Anselmo Duarte, Odete Lara, Milton Ribeiro, Hélio Souto e Ricardo Campos. O escritor estreia, como ator, em 1961, com Mulheres e milhões, junto a nomes, à epoca famosos, como Odete Lara, Glauce Rocha e Jece Valadão, e ganha o prêmio Saci de melhor ator. Um ano após, atua em $A$ ilha, ao lado de Eva Vilma, Elizabeth Hartman, Liris Castelani e Laura Verney, com direção de Walter Hugo Khoury.

Do mesmo modo que na literatura, as narrativas adaptadas conduzem os espectadores à intimidade da família brasileira, aos sentimentos e à descoberta da natureza, entre outros conteúdos de um longo processo de civilização inscrito na experiência colonial da escravização indígena e africana. Essas narrativas, sobretudo, ampliam "a literatura para além dela mesma" (Mollier, 2019) e, sob o enfoque sociológico, tornam-se chave das apropriações e trocas assimétricas propiciadas pela circulação ampliada na indústria da cultura. Nessa direção, os temas do controle e transbordamento das emoções e normas internalizadas, agindo nas disposições mentais e comportamentais de milhares de leitores espalhados pelo mundo - problema de ordem psicogenética, como diria Norbert Elias ([1990] 2010) -, guiam o convívio com Zezé. A figura triste-alegre de criança deixa o livro e entra nas telas do cinema e da televisão, tomando a forma de alegoria no desfile do carnaval. Não sem causar reservas e controvérsias. $\mathrm{O}$ movimento de afirmação da autoria em José Mauro su- 
punha encontrar os leitores nas salas de cinema e no carnaval, espaços de recepção onde sua obra era socialmente aceita e reconhecida. Na coluna de crítica de cinema do "Caderno B" do Jornal do Brasil, de 26 de abril de $1970^{16}$, o anúncio publicitário do filme $O$ meu pé de laranja lima estabelecia a seguinte correlação: "um filme para ver (e rir, e chorar, e enternecer); um livro para ter (e reler, e guardar, e reler)". E mais abaixo, "A história triste-alegre de Zezé, vivida no cinema pelo garoto Júlio César Cruz. A perenidade do livro e a fugacidade do filme". Um mês depois, no mesmo jornal, a coluna de cinema assinada por Sérgio Augusto compara a adaptação do romance à imaginação literária do Almanaque Capivarol, guia prático e informativo para a satisfação imediata do gosto e curiosidade do público:

Aos lugares-comuns do romance que faz apelo ao sentimentalismo vulgar, ao bucolismo caipira, à nostalgia da infância, correspondem os clichês do cinema de comiseração calculada: adultos combalidos e comovidos vertendo lágrimas em primeiro plano, a pobreza do pai representada pela câmera a meia distância de um decor despojado como nos velhos melodramas de teatro expressionista, dosadas pausas para gracinhas chistosas, etc. (Augusto, 1970).

O crítico de televisão Valério Andrade (1970), por sua vez, chamava a atenção do leitor para a grande cartada da TV Tupi no final da temporada de 1970 ao lançar uma novela adaptada de enredo já consagrado como sucesso em livro e filme. As laranjas-limas transformavam-se em pepitas de ouro caídas no gosto do público, ironizava o crítico, ao se referir a José Mauro como um obscuro escritor editado recorrentemente pela Editora Melhoramentos. Adaptado para o cinema por Herbert Richers, dirigido por Aurélio Teixeira e protagonizado por um ator selecionado no programa dominical de Flávio Cavalcanti, Andrade fazia sua aposta de que a telenovela ampliaria em escala muito maior o pacto firmado anteriormente entre o romance, o filme e o público. Ou melhor, ampliaria o diálogo iniciado pelo livro e prolongado pelo cinema. Triunfo do progresso técnico da indústria da cultura, a novela de televisão já provara ter vindo para ficar como narrativa seriada que se impunha.

Àquela altura, quando se iniciavam as transmissões televisuais via satélite para todo o Brasil, já se faziam sentir as alterações que tornaram as telenovelas programas de ampla repercussão em termos de audiência e arrecadação publicitária (Ortiz, Ramos e Borelli, 1989). De um lado, a utilização do videotape e de amplos ambientes cenográficos, pela TV Excelsior, alterou o modo de produção das telenovelas, as

16. Jornal do Brasil, Rio de Janeiro, 26 abr. 1970. Disponível em http://memoria.bn.br/docreader/DocReader.aspx ?bib=030015_09\&pagfis=7079, consultado em set. 2019. 
quais passaram a ser exibidas diariamente, ocupando a faixa de horário de maior valor comercial. De outro, o extraordinário sucesso obtido por Beto Rockeffeler, em 1965, assinada por Cassiano Gabus Mendes, com direção de Lima Duarte, deslocara definitivamente as tramas para o cotidiano brasileiro.

Na medida em que a experiência da Globo reúne um e outro desenvolvimento, sintetizando-os, o crescente sucesso da telenovela indica a ampliação das margens da cultura. Realizada por produtores especializados e remunerados, sobretudo voltada ao consumo mercantilizado na direção da linguagem audiovisual e da produção da cultura de massa, a telenovela pressiona o mercado editorial a favor de uma redelimitação do texto literário. A adaptação do romance $O$ meu pé de laranja lima para o formato de dramaturgia televisiva ilustra um episódio na formação desse novo vetor sociocultural, com repercussões nos planos da produção de bens simbólicos, dos regimes de autoria e das sensibilidades das recepções.

Nesse sentido, enquanto instrumento teórico-analítico, o emprego da noção de cultura popular de massa possibilita cotejar tramados sociossimbólicos como o descrito acima, em que as tradições seculares ou não do popular estão relacionadas com a produção industrializada e com os esquemas da racionalização técnico-burocrática. E assim, passam ao primeiro plano as táticas realizadas no consumo, negociações e estratégias empregadas na produção, nas quais as modalidades a serem utilizadas no reconhecimento, cognitivo e afetivo, dos bens simbólicos pelas audiências circulam por instâncias diversas, como as matrizes culturais vinculadas às tradições dos diversos gêneros de cultura.

Vê-se, então, o aumento do alcance empírico e analítico proporcionado pela lente teórica da cultura popular de massa, voltada aos diálogos intertextuais e à contrapartida das situações multiculturais e dos processos intra e intermídias. No mesmo andamento, considera a absorção de novos quadros intelectuais e artísticos nos esquemas empresariais mercantis, articulada à ampliação do mercado de bens simbólicos, quando aliada às ecologias sociotécnicas de comunicação.

Embasado na articulação entre a concepção de hegemonia em Gramsci e a proposição foucaultiana sobre a pulverização do poder - descentrado na direção das micropolíticas -, Jesus Martin-Barbero (2009) recusa a ênfase unilateral concedida aos meios de comunicação de massa, para se ater às mediações pelas quais se firmam pactos simbólicos entre mídias e audiências. A seu ver, quando se trata dos bens culturais reunidos sob o guarda-chuva da cultura popular de massa, em especial na América Latina, o enigma em torno das afinidades eletivas estabelecidas entre a produção da indústria cultural e o tão heterogêneo como múltiplo espectro de públicos elucida-se, em parte, considerando o papel de matriz cultural desempanhado pelo melodrama. Essa matriz estende-se do período colonial, passando pela montagem dos estados 
nacionais, até a configuração da estrutura urbano-industrial e de serviços em diversos países do subcontinente. De acordo ainda com o autor, o melodroma diz respeito a um mesmo tecido de sentimentalismo cujas dimensões contemplam distintas faces da produção do sentido e dos modos de afirmação de consciências e sensibilidades. Nele, sobressai o apelo direto às lágrimas de alegria e dor como manifestação do apreço aos excessos na exposição pública de toda sorte de cromatismos emocionais, ressaltando o desprezo para com os pruridos do distanciamento intelectualista em relação às descargas afetivas imediatas.

Essa tessitura em que os contrastes afetivos berrantes são priorizados, para ele, avança e retroage sobre classes sociais, grupos étnicos, identidades regionais e outros marcadores sociais. $\mathrm{O}$ trânsito por tão heterogêneo e imenso conjunto de camadas sociais se dá pelos caminhos da enraizada e multifacetada cultura oral, propagada em formatos musicais - da prosa e poesia de domínio autoral coletivo, mas também dos desenhos coreográficos e das encenações teatrais populares -, posteriormente acoplada à radiodifusão e aos formatos audiovisais, seja com o cinema, seja com os gêneros que perfazem a programação televisiva.

Sob esse ponto de vista, o traço sentimental perceptível em José Mauro de Vasconcelos - e que, muitas das vezes, pesou contra a legitimação da sua produção ante o cânone nacional - manifesta um ponto de interseção entre a formação de um padrão de subjetividade, ao qual a sua própria estrutura psíquica se integrou, e as estratégias de composição formal-estético e o posicionamento mercadológico dos bens simbólicos da cultura popular de massa no Brasil do pós-Segunda Guerra. Não nos parece inadequado conceber, nessa interseção, importante condição de possibilidade para a acomodação do escritor e seus romances numa intertextualidade abrangente, no escopo da qual os agenciamentos autorais e bens literários são redimensionados, levando-se em conta a retomada da mesma matriz cultural do melodrama. Agora, porém, sob as coordenadas de um sentimentalismo lúdico que, na promoção da evasão pelo divertimento, contracena com os imaginários oníricos da infância, do maravilhamento fabuloso e do sobrenatural popular afro-ameríndio, este último já racionalizado na categoria de folclore pelo discurso erudito.

Talvez possamos apurar o argumento acima deixando de lado o âmbito próprio da indústria cultural para focar outra adaptação do mesmo romance de José Mauro de Vasconcelos. Para o carnaval de 1970, a escola de samba Mocidade Independente de Padre Miguel propõe também a recriação de $O$ meupé de laranja lima. Cabe abrir um breve parêntese com a finalidade de assinalar a atmosfera sócio-histórica de quando o universo ficcional de Vasconcelos chegou ao carnaval. Naquela virada de década, os desfiles desses grêmios carnavalescos já atraíam multidões para os andaimes de arquibancadas armados na avenida Presidente Vargas, no centro do Rio de Janeiro. 
Um gradual e contínuo processo de diferenciação de públicos escalonados pela capacidade monetária de acessar distintas áreas de visão do evento - iniciava-se, por exemplo, a instalação de camarotes - entrevia a expansão da base social (em termos das classes e grupos de prestígio, à maneira de artistas vinculados à indústria cultural) que não apenas assistia a ele, mas participava como desfilante, além de atuar na sua concepção/produção e administração. Base social acrescida, ainda, pela participação sempre maior de visitantes nacionais e estrangeiros, na medida em que a folia carioca e o desfile das escolas de samba, em particular, iam para a vitrine de uma cidade cujo turismo internacional estava em ascensão. Introduzida no início da década anterior, a transmissão televisiva só agora trocava a tônica jornalística - capturando momentos para apresentar como notícias -, em nome da prioridade posta na focalização do evento como um espetáculo integrado a ser exposto em sua totalidade, com o status de show da cultura brasileira a céu aberto veiculado para o país inteiro.

O cenário descrito acima sinaliza condicionantes sócio-históricos cujos efeitos se faziam presentes, à época, de modo ainda incipiente. Mais tarde, na segunda metade da mesma década de 1970, suas repercussões se aprofundaram a ponto de embasar na triangulação mídia televisual, turismo e mercado fonográfico a fixação dos desfiles das escolas de samba entre os bens da cultura popular de massa (Farias, 2006). Ainda assim, naquela virada dos anos 1960 para 1970, os mesmos condicionantes incidiam naquela decisiva propriedade interna à composição formal do gênero cultural desfile de carnaval, a saber, o imperativo de tomar as vias públicas e obter diferenciação funcional frente a outras modalidades de diversão afins. $O$ desafio permanente aos agenciamentos que o realizam gira em torno da busca de tomar o espaço público como elemento apto a estabelecer significação com as plateias.

Se na sua versão escola de samba, a princípio, predominou o desfile de carnaval como a passeata de um grande coral embalado pela percussão coletiva da bateria, ao longo da década de 1960, com a entrada de artistas plásticos especializados, ligados à academia e ao mundo dos espetáculos, dá-se a transformação dessa característi$\mathrm{Ca}^{17}$. O comando estético do diretor de harmonia e o protagonismo artístico do compositor do samba-enredo se deslocam para o carnavalesco, sendo este o artífice

17. Liderado pelo professor da Escola de Belas Artes e cenógrafo do Teatro Municipal do Rio de Janeiro, Fernando Pamplona, em 1950 se formou um círculo artístico-intelectual, consagrado na história do carnaval carioca, sob a denominação de "Grupo do Salgueiro". Ao assumir o comandado artístico da escola de samba Acadêmicos do Salgueiro, ao grupo é atribuído um montante de inovaçôes que alterou o vetor estético dos desfiles, o qual deixou de priorizar a horizontalidade do canto e da dança em nome da verticalidade dos adereços de mão, estandartes e carros alegóricos. Transformações essas relacionadas a mudanças na concepção dos temas-enredos: de um lado, deu-se prioridade a personagens anônimos da formação do povo brasileiro; de outro, a escolha do tema responde à necessidade de prover a apresentação da escola de diferentes ambiências plástico-visuais. 
responsável por conceber o tema-enredo e idealizar as ambiências indumentárias e cenográficas que deambularão frente aos olhos situados nas arquibancadas. O requisito de proporcionar imagens de grande impacto visual é internalizado nos projetos carnavalescos das escolas e aos poucos se naturaliza, antecipando-se à escolha dos temas-enredos e, com isso, influenciando o plano percussivo-musical e a evolução dançada dos $\operatorname{cortejos}^{18}$.

Extrapola os objetivos deste texto esmiuçar as razões de a participação das diferentes escolas de samba nesse esquema sociocultural ocorrer de modo desigual, já que algumas se puseram na vanguarda e firmaram-se protagonistas da nova cena, enquanto outras tiveram uma inserção tortuosa nela. Localizada na periferia suburbana do Rio de Janeiro, ainda de fundação recente em relação às escolas mais tradicionais, a Mocidade Independente de Padre Miguel ocupava, então, posição secundária na hierarquia das competidoras ao título do carnaval carioca. Sem financiadores e maiores atrativos, a agremiação lutava por se manter no grupo principal dos desfiles. Para os críticos especializados, era somente uma bateria "rodeada de escola de samba"; afinal, seu único destaque estaria no desempenho do seu conjunto de ritmistas, comandado pelo mestre André - inventor das paradinhas ${ }^{19}$. Sempre às voltas com o risco de rebaixamento para a divisão inferior do torneio das escolas de samba, à administração da Mocidade não restara senão encontrar alternativas para reverter a situação da escola. Calcada no prestígio de um best-seller lançado em 1968 e que logo iria também para as telas de cinema, a opção pelo enredo $O$ meu pé de laranja lima vem no caudal das possibilidades de exploração plástico-visuais e musicais vislumbradas com a sua realização. Tratava-se de uma temática nacional enraizada no folclore e na cultura popular, mas do ponto de vista da imaginação infantil, na qual se tornam cúmplices o lúdico e o onírico ${ }^{20}$.

18. Entre a segunda metade da década de 1940 e meados dos anos de 1960, a elaboração do samba-enredo confirmou um padrão notabilizado por uma narrativa longa, à maneira de uma epopeia, fazendo recurso ao léxico rebuscado da língua portuguesa. Nesse ínterim, sagra-se o nome do compositor Silas de Oliveira, da escola de samba Império Serrano. Em especial com a ingerência do compositor Martinho da Vila, deu-se o que poderíamos chamar de um despojamento desse gênero musical em termos de narrativas mais enxutas e com emprego de palavras coloquiais. Já na década de 1970, inicia-se a funcionalização do samba-enredo, porque ele passa a ser definido como um retrato cantado do espetáculo audiovisual.

19. As chamadas "paradinhas" aparecem nos desfiles de 1958. Em razão de um deslize do mestre André, permaneceram tocando apenas os repiques da bateria da Mocidade Independente de Padre Miguel. Depois de alguns instantes, ao retomar o comando com o assobio do seu apito, o mestre ordenou que os demais instrumentos voltassem a percutir. Sem conhecimento do que havia acontecido, a plateia respondeu empolgada ao efeito, gritando "olé!".

20. Jornal Carnavalizados: "Para muitos, o carnaval é uma espécie de conto de fadas: um reino distante, onde tudo pode acontecer. O carnaval permite se ficcionar, tornar-se ficção, ser outro que não eu mesmo. Ele é capaz de formular uma verdade diferente, não oficial, sobre o mundo e sobre os sujeitos, 
Assinada por Gabriel Nascimento e Dario de Castro, também responsáveis pela execução do projeto de figurinos e alegorias/adereços, a sinopse do enredo da escola para o carnaval de 1970 tem na infância um fio comum dramatúrgico, concebido na figura da duração de uma vida humana, a ser esticado no desenrolar do desfile. Desdobrada em seus muitos estágios etários (criança, juventude, amadurecimento, velhice), na sua progressividade, a vida guardaria sempre as lembranças da sua fase inaugural, mesmo quando há dificuldades enfrentadas pelo adulto e/ou dores que geram lágrimas do corpo envelhecido:

Baseada no livro de José Mauro de Vasconcelos O meu pé de laranja lima.

Para cada poema, um prefácio:

E foi assim que ganhei a minha roupa de poeta...

Se fôssemos simbolizar as coisas da vida, poderíamos dizer, ela e o amor que nela sentimos nada mais são que um grande livro com pequeno prefácio.

Um livro sério, tendo prólogo poético. Enredo enorme, confuso, espesso, complexo, levando de frente um grande poema!

Comparando nossas diversas idades, vemos que os cantos são mais nos começos, ficando os choros, para o fim.

Os nossos corações pensam que é uma escada a passagem das idades, subimos, andamos e ultrapassamos crescendo!...

Há certa infância que segue os dias de um ancião, assim como se nota muita precocidade nos dias inaugurais de uma criança!

Só somos perfeitos quando sabemos ter em nossas quadras específicas notas com ressaibos simpáticos e resquícios de saudade!

Mesmo assim, sabemos que há mais luz em seus começos do que nos seus fins. O sabor agradável da infância passa quando chegam os anos amadurados!

para construir novas reflexões. É uma festa que rompe as barreiras conservadoras do sistema oficial, que dramatiza o sujeito em inúmeras máscaras e o faz navegar num mar agitado feito de plástico, tinta e lantejoulas. Nos contos de fadas, a gata borralheira vira princesa; no carnaval, o moço que vende peixe na feira vira mestre-sala. O carnaval é mágico, é lúdico, tal qual uma história infantil. Todos podem ser o que quiserem. E misturar esses dois universos, carnaval e temas infantis, é ler um conto de fadas através de fantasias, alegorias e samba. Esse espírito carnavalesco se une perfeitamente com o lúdico da infância e ativa nossa memória afetiva, através de desfiles onde os personagens fantásticos são inseridos, ora como fios condutores, ora de modo mais fidedigno, com a história apenas adaptada e carnavalizada. Muitas das características dos contos de fadas encontram-se no viver carnavalesco. Esse mundo às avessas, onde a realidade é surreal. Personagens míticos, encantados ou reais, trabalhando a realidade, mostrando outras culturas e fortalecendo nossa própria identidade. $\mathrm{O}$ universo infantil pode propiciar para os carnavalescos um mundo vasto de possibilidades de brincar com as cores. O mundo é o real, e cabe ao carnavalesco torná-lo encantado" ("Trinta e dois enredos com a temática infantil", 2017). 
Todos os prefácios são mais cantantes do que os índices! Isto é a vida! E não podemos chorar os fatos porque temos que progredir, colhendo frutos diferentes, nas diferentes quadras! Cada um guarda, pois, o seu poema de luz ou a sua lembrança mofada, para o resto de seus dias. Por isso olho às vezes o céu, e vejo longas luzes se movendo como ondas longas do mar, ou então girando ou saltando, nunca paradas.

Penso serem as grandes luzes, sem dúvida, os espíritos das criancinhas que nasceram e morreram. Tiveram sempre nos olhos um mar de lágrimas rolando, sem poder ter tido um mar de ondas de astros, em que passam e sobem, debanda para o infinito. Anjos sorrindo em busca do reino da poesia... O bom reino da imaginação fazendo fronteiras com a vida!

Procuramos animar, mais e mais àqueles que hoje estão na idade em que estamos, quando também cantávamos e escrevíamos talvez o poema do nosso prefácio da vida.

Os autores definem a sinopse como um "prefácio" da vida apreendida à maneira de um poema; logo, um texto. Momento em que o enredo se concretizará em atos, $\mathrm{o}$ desfile consiste em um metatexto no qual a vida poderá ver-se no seu duplo simbólico, como se contemplasse a si mesma em um espelho. Constituindo-se igualmente em uma escritura, mas audiovisual, o desfile se equaliza em sincronia com o romance que o inspira. Ambos compartilham da característica de verter elementos do real histórico em elementos da sua formação ficcional; portanto, são cúmplices enquanto criações imaginativas, aptas a promover a evasão pelo entretenimento dos seus públicos. No caso do enredo da Mocidade, a vida em questão em $O$ meu pé de laranja lima não é uma em particular, e sim a fábula do próprio desenrolar da existência da pessoa humana como uma odisseia, com episódios de alegria e sofrimento. Manifesto na logomarca do carnaval da escola em 1970 (ilustração 1), o desenrolar da trama se dá em torno do personagem Zezé: essa criança ficcional incita as lembranças pelas quais as fantasias da infância chegam ao adulto; estas, se lhe fomentam saudades, podem também torná-lo resiliente ante as dificuldades enfrentadas. Assim, ao encenar essas recordações da era da inocência infantil, em comum com a literatura, embora por um breve período, o desfile conduziria a plateia ao lugar tecido pelas projeções imaginativas lúdicas, em que a excitação dos sentimentos e suas expressões têm por motivação as brincadeiras avessas a qualquer limitação.

Composto por dois dos mais consagrados nomes da ala de compositores da Mocidade, Gibi e Arsênio, o samba-enredo da escola naquele ano explicita o propósito de tornar o desfile uma grande viagem às muitas feições da fantasia infantil. Daí, convida o público a entrar em uma brincadeira de roda. E, já de saída, recorre ao "era uma vez", tão sugestivo em termos da sua potencialidade de fabular. Como se fosse aberto um portal por onde passarão os adultos da plateia carnavalesca, desde agora eles percorrem compartimentos de um castelo encantado, erguido a cada adorme- 


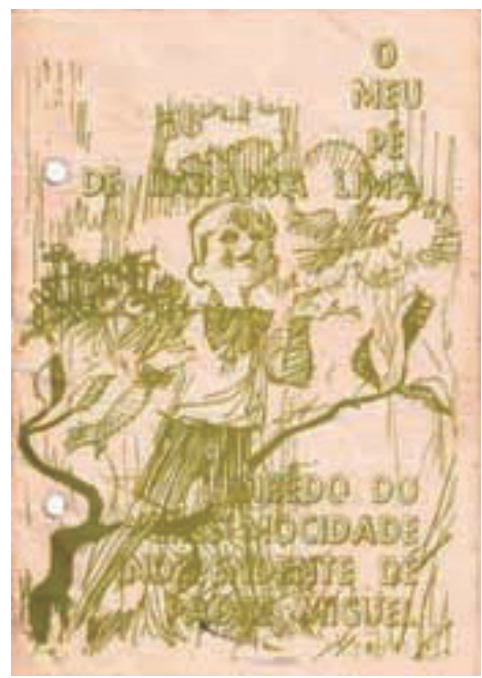

Ilustração 1 Logomarca do enredo de 1970.

cer de uma criança, deparando-se momento a momento ou simultaneamente com personagens sagazes em ludibriar a dureza objetiva das determinações cotidianas. Abandonam tudo que os torna infelizes para realizarem um espetáculo ao sabor das suas emoções mais autênticas; quer dizer, menos corrompidas pelas injunções da vida "séria":

Era uma vez

Frase que traz felicidade

Às pequeninas majestades

No seu reino de ilusões

Reis, fadas e rainhas

As estórias contadas pelas dindinhas

Entre outras seduções

Dominam suas imaginações

Nas inocentes travessuras

Merecem ternura e muita compreensão

No seu reino de alegria

Do seu mundo de fantasia

Não as devemos despertar

Para as tristezas enegrecidas

Dos infortúnios da vida

Oh como é triste fazer a criança chorar 
Oh crianças queridas

Alegrias coloridas

Esperança de toda a geração

Eis a mensagem

Continuem o espetáculo

Ao sabor dos seus corações
Ah eu entrei na roda
Eu entrei na roda-dança
Eu entrei na contradança
Eu não sei dançar

O episódio do carnaval da Mocidade Independente de Padre Miguel, em 1970, nos parece ilustrativo da interdependência estabelecida entre práticas e bens culturais no delineamento e funcionamento da cultura popular de massa. Para voltar à noção de mediação, por certo as adaptações do romance $O$ meu pé de laranja lima para outros suportes expressivos estendem as margens de popularização da obra e do seu autor. Mais ainda, no instante em que mobilizam signos que não somente $o$ linguístico na codificação da mensagem, pressionam o alargamento da concepção mesma do texto literário. No mesmo diapasão, porém, cabe reconhecer estarem na narrativa do livro propriedades formais transformadas em matéria-prima simbólica para os diferentes usos feitos pelo cinema, a televisão e o carnaval. Propriedades essas relativas à sensibilidade do autor em ir e selecionar traços do acervo da matriz cultural popular; traços talvez inscritos na sua formação sentimental e que são capazes de gerar reconhecimento e manifestações emocionais naquelas estruturas psíquicas também, de um modo ou de outro, decorrentes de processos civilizadores em que o melodrama fez parte dos fundos coletivos de saberes transmitidos em intercursos geracionais e participou da produção de subjetividades.

Por um lado, nesse tramado, complicam-se os critérios dos regimes de autoria porque, se não descartam a assinatura individualizada, agregam outras subjetividades criadoras (o diretor do filme, a autora da novela, os carnavalescos, os compositores do samba). Por outro lado, cada criação resultante das leituras do romance lhe edita e lhe acresce aspectos: na telenovela, há personagens não encontrados no livro; no samba-enredo, são sobreacentuados os elementos imaginativos e oníricos em detrimento das demais componentes da narrativa. Nesse sentido, podemos concluir que O meu pé de laranja lima resulta em uma teia intertextual na contrapartida de um igualmente abrangente encadeamento institucional e sociotécnico. A figuração desse amplo e complexo arranjo pode sugerir a ideia de "sujeira", isso se considerarmos as 
mútuas pressões entre ingredientes tão heteróclitos entre si. Sob a perspectiva da unidade da autoria, algo assim precipita a conclusão de que o princípio da autonomia da forma literária está sendo posto em xeque. Na medida, porém, em que se examinam as mediações pelas quais se define uma codificação recíproca entre os mesmos elementos, somos levados a concluir estar em questão a emergência de uma outra forma cultural. E, só a partir do seu delineamento, torna-se possível verificar o "dentro" e o "fora” que lhe são relativos; logo, os critérios normativos da autonomia e da heteronomia estão referidos à composição dessa forma.

Referências Bibliográficas

Aguiar, Luiz Antônio. (2018), "A literatura de O meu pé de laranja lima”. In: Vasconcelos, José Mauro de. O meu pé de laranja lima. São Paulo, Melhoramentos.

Andrade, Valério. (dez. 1970), "O meu pé de laranja lima”. Jornal do Brasil, "Caderno B”, Rio de Janeiro, p. 2. Disponível em http://memoria.bn.br/docreader/DocReader.aspx ?bib=03 0015_09\&pagfis=22016, consultado em set. 2019.

Augusto, Sérgio. (maio 1970), “O meu pé de laranja lima”. Jornal do Brasil, "Caderno B", Rio de Janeiro, p. 4. Disponível em http://memoria.bn.br/docreader/030015_09/7863.

Barroso, Haydee. (1978), Vida y saga de Jose Mauro de Vasconcelos. Buenos Aires, Libreria El Ateneo Editorial.

Bourdieu, Pierre. (2009), "Les conditions sociales de la circulation internationale des idées". In: SAPIRO, G. L'espace intellectuel en Europe. De la formation des États-nations à la mondialisation $X I X^{e}-X X I^{e}$ siècle. Paris, La Découvert.

Bourdieu, Pierre. (2001), Science de la science et réflexivité. Paris, Raison d'Agir.

BuLLETIN d'Analyses de Livres pour Enfants (1971), Paris, La Joie par les livres, 24.

CAGno, Carmen. "Um novo round: Zé Mauro versus crítica”. (out. 1979), Jornal da República, “Literatura”, São Paulo. Disponível em http://memoria.bn.br/DocReader/194018/775.

Cascudo, Luís da Câmara. (1944), “Apresentação”. In: VAsconcelos, José Mauro de. Banana brava. Rio de Janeiro, Coleção Centenário de Luís da Câmara Cascudo, 1944.

Casanova, Pascale. (2007), "Reflexiones sobre algunos usos prácticos de la noción de autonomia relativa”. In: Champagne, Patrick; Pinto, Louis \& Sapiro, Gisèle. Pierre Bourdieu, sociólogo. Buenos Aires, Nueva Visión.

Dantas, Audálio. (out. 1979), “José Mauro: 18 livros e muitos amores”. Revista Realidade, Abril. Elias, Norbert. "Le concept freudien de société et au-delà”. ([1990] 2010), In: Au-delà de Freud. Sociologie, psychologie, psychanalyse. Paris, La Découverte.

FARIAs, Edson. (2006), O desfile e a cidade: o carnaval-espetáculo carioca. Rio de Janeiro, E-Papers. Freyre, Gilberto. (2010), Encontros, a arte da entrevista. Rio de Janeiro, Azougue. 
JORNAL DO BRASIL. (abr. 1970), Rio de Janeiro. Disponível em http://memoria.bn.br/docreader/ DocReader.aspx ?bib=030015_09\&pagfis=7079, consultado em set. 2019.

JURT, Joseph. (2014). Naciones literarias: una sociología del campo literario. Córdoba, Villa María, Eduvim.

LAHIRE, Bernard. (2006), La condition littéraire: la double vie des écrivains. Paris, Éditions La Découverte.

LEÃo, Andréa Borges. (2018), "José Mauro de Vasconcelos: o intérprete e as traduções do Brasil”. Politica \& Sociedade, 17 (39): 141-168. Disponível em https://periodicos.ufsc.br/ index.php/politica/article/viewFile/2175-7984.2017v17n39p141/37833.

“Livros Novos". (out. 1948), O Cruzeiro, “No Mundo dos Livros”. Disponível em http:// memoria.bn.br/DocReader/003581/56094, consultado em 4/1/2020.

Machado, Aluízio. (mar. 1979), “Feira do Livro de Buenos Aires: 100 mil títulos para meio milhão de compradores". Jornal do Brasil, Rio de Janeiro. Disponível em http://memoria. bn.br/docreader/DocReader.aspx ?bib=030015_09\&PagFis=195919, consultado em 20/12/2019.

Martin-Barbero, Jesus. (2009), Dos meios às mediaçôes. Rio de Janeiro, ufrJ.

Mollier, Jean-Yves. (2019), "À procura de um imaginário melodramático no século XIX: imprensa, folhetins e romances. Da sua produção a sua recepção”. Revista Moara, 52: 73-87.

Ortiz, Renato; Ramos, José Mário O. \& Borelli, Silvia Helena S. (1989), Telenovela: história e produção. São Paulo, Brasiliense.

Pinheiro, Fernando Antonio. (2014), “O rei do outro polo: Paulo Coelho na literatura brasileira”. In: Miceli, Sergio \& Pontes, Heloisa. Cultura e sociedade. Brasil e Argentina. São Paulo, Edusp.

SAlES, Herberto. (1988), Subsidiário: confissões, memórias e histórias. Rio de Janeiro, José Olympio.

SorÁ, Gustavo. (2003), Traducir el Brasil: una antropología de la circulación internacional de ideas. Buenos Aires, Libros del Zorzal.

“Trinta E dois Enredos com a temática infantil”. (out. 2017), Carnavalizados. Disponível em http://carnavalizados.com.br/noticias/32-enredos-com-a-tematica-infantil/, consultado em $14 / 2 / 2020$.

Vasconcelos, José Mauro de. ([1963] 1972), Doidão. São Paulo, Melhoramentos.

VAsconcelos, José Mauro de. (1969), O homem e a obra. Ribeirão Preto, El Dorado.

Vasconcelos, José Mauro de. ([1968] 2018), O meu pé de laranja lima. São Paulo, Melhoramentos.

VenAYRE, Sylvain. (2002), La gloire de l'aventure : genèse d'une mystique moderne. 1850-1940. Paris, Aubier. 


\section{Resumo}

\section{Literatura e audiovisual em José Mauro de Vasconcelos}

Este artigo abre um debate sobre as condições de circulação e recepção transnacional das obras como fator de diferenciação nas carreiras literarias nacionais. O objetivo central é mostrar de que modo as dinâmicas da tradução funcionam como recursos possíveis para reconhecimento e consagração, considerando escritores posicionados nas margens da produção simbólica nacional. O percurso do escritor José Mauro de Vasconcelos, cuja obra descreve movimentos entre a literatura e o audiovisual a partir de 1950, estabelece relações explicativas de alto rendimento analítico com a problemática da recepção transnacional da produção brasileira. A confluência e a transferência entre cânones nacionais, além de aproximar escalas de observação dos regimes de autoria, vinculam-se à circulação da literatura popular sentimental para além dela mesma. Palavras-chave: Literatura e audiovisual; Literatura popular sentimental; Circulação transnacional da literatura; Literatura e carnaval.

\section{Abstract}

On the borders of symbolic circulation. Literature and audiovisual in José Mauro de Vasconcelos This article opens a debate about the transnational circulation and reception conditions of the works as a differential factor in the national literary careers. The main objective is to show in which way the dynamics of translation work as possible resources for recognition and consecration, considering writers positioned on the borders of national symbolic production. The path of the writer José Mauro de Vasconcelos, whose work describes movements between literature and audiovisual from 1950, establishes explanatory relations of high analytical performance with the problematics of the Brazilian production transnational reception. The confluence and the transfer between national canons, aside from approximating the observation scales of the authorship regime, is linked to the sentimental popular literary circulation beyond itself. Keywords: Literature and audiovisual; Sentimental popular literature; Transnational literature circulation; Literature and carnival. 
Texto recebido em 31/3/2020 e aprovado em 9/4/2020.

DOI: 10.11606/0103-2070.ts.2020.168354.

Andrea Borges Leão é pesquisadora do Cnpq. Professora do Departamento de Ciências Sociais e do Programa de Pós-graduação em Sociologia da Universidade Federal do Ceará. Líder do Grupo de Estudos em Cultura, Comunicação e Artes (GECCA/UFC) e membro do grupo de pesquisa Cultura, Memória e Desenvolvimento (CMD/UnB).E-mail: aborgesleao@gmail.com. Edson Farias é pesquisador do CNPq. Professor Programa de Pós-graduação em Sociologia da Universidade de Brasília e do PPG em Memória: Sociedade e Linguagem da Universidade Estadual do Sudoeste da Bahia (Uesb). Líder do grupo de pesquisa Cultura, Memória e Desenvolvimento (CMD/UnB). Editor da revista Arquivos do CMD. Membro do Conselho do Museu AfroDigital Carioca. Membro do Comitê de Imagem e Som da Associação Nacional de Pós-graduação e Pesquisa em Ciências Sociais (Anpocs).E-mail: nilosed@gmail.com. 